\title{
CULTURAE DESENVOLVIMENTO SUSTENTÁVEL NO PANTANAL MATO-GROSSENSE: entre a tradição e a modernidade
}

\author{
Onélia Carmem Rossetto* \\ Antonio C. P. Brasil Junior**
}

\begin{abstract}
Resumo: Apesar de estarem ocupados por diferentes grupos sociais há centenas de anos, algumas parcelas das áreas rurais dos pantanais mato-grossenses ainda mantêm parte das suas características naturais preservadas. A pecuária, principal atividade econômica, desenvolveu-se sem praticamente alterar a dinâmica da paisagem. Como correlato, a imagem construída sobre os seus habitantes é mencionada como exemplo de uso sustentável dos elementos naturais. Apesar deste estereótipo positivo, pouco se sabe ainda sobre esses conhecimentos que, devido à modernidade, muitas vezes se perdem ou assumem outras formas. O presente texto inscreve-se nessa perspectiva. Seu principal objetivo é investigar os saberes pantaneiros, que resultaram em formas peculiares de organização da paisagem e em aspectos específicos da cultura material. Concluiu-se que, com a modernização e as alterações na cultura material, principalmente a substituição do pasto nativo pelo exótico, o equilíbrio da paisagem natural encontra-se ameaçado. A sustentabilidade cultural, entendida como um sistema aberto, passível de alterações, é um indicador de grande relevância na busca do desenvolvimento sustentável.
\end{abstract}

Palavras-chave: Pantanal, paisagem cultural, desenvolvimento sustentável.

\section{Introdução}

A ocupação dos pantanais mato-grossenses por habitantes não índios iniciou-se por volta do século XVI pelos europeus, através dos

\footnotetext{
* Professora do Departamento de Geografia, Universidade Federal de Mato Grosso.

** Professor do Centro de Desenvolvimento Sustentável, Universidade de Brasília (CDS-UnB). Artigo recebido em 11 ago. 2003; aprovado em 2 out. 2003.
} 
caminhos desenhados pelo Rio Paraguai e seus afluentes. Esta região passou a ser denominada 'Pantanal', em meados do século XVIII, pelos monçoeiros, para definir os campos alagados com várias lagoas e sangradouros (Costa,1999).

As fazendas do Pantanal do Padre Inácio - Jauru têm suas origens em 1873, quando Luiz Melo Pereira e Cáceres, então governador-geral da capitania de Mato Grosso, fundou a povoação de Casalvasco, para impedir a entrada de espanhóis e proteger parte da fronteira oeste do Brasil, transformando o local e os grandes campos em fazenda real, pertencente ao rei de Portugal.

Por volta de 1820 , o lugarejo entrou em decadência e foi devolvido à Província de Mato Grosso, permanecendo como Fazenda Nacional da Caiçara, nas cercanias de Cáceres. O local era constituído de pantanais e terras pobres e extensas que terminavam na Serra do Caeté, limitadas pelos rios Paraguai, Cabaçal e Jauru (Cabral, 1963).

Nas fazendas pantaneiras, a identidade étnica foi composta pela preponderância do caboclo regional, descendente de bororo, de pareci, de guató, de chiquitos ou índios bolivianos (Corrêa Filho, 1946). A essas etnias juntou-se o negro africano e o branco de origem espanhola ou portuguesa, alguns descendentes dos antigos bandeirantes paulistas que, com o fim do ciclo das bandeiras, no século XVIII, contribuíram para que se formasse

...um lençol de cultura caipira, com variações locais, que abrangia parte das capitanias de Minas, Goiás e mesmo Mato Grosso. Cultura ligada a formas de sociabilidade e de subsistência que se apoiavam, por assim dizer, em soluções mínimas, apenas suficientes para manter a vida dos indivíduos. (Candido, 1964, p. 57).

A simplicidade extrema dos estilos de vida é uma característica que acompanha as identidades que habitam as fazendas pantaneiras independentemente da sua posição no grupo social, sejam eles fazendeiros, pequenos sitiantes, peões ou capatazes.

Apesar de estarem ocupados por essas identidades sociais há centenas de anos, os pantanais mato-grossenses ainda mantêm parte da área rural com suas características naturais originais. A pecuária, principal atividade econômica, explorada em Mato Grosso desde 1737 
(Borges, 1991) desenvolveu-se sem praticamente alterar a dinâmica da paisagem matriz. Como correlato, a imagem construída sobre seus habitantes é mencionada como exemplo de uso sustentável dos elementos naturais.

A despeito deste estereótipo positivo, pouco se sabe ainda sobre esses conhecimentos que, devido à modernidade, muitas vezes se perdem ou assumem outras formas. O presente texto inscreve-se nessa perspectiva e seu principal objetivo é investigar os saberes pantaneiros que resultaram em formas peculiares de organização da paisagemmarca e em aspectos específicos da cultura material.

Adotaram-se, como procedimentos metodológicos, duas técnicas relacionadas entre si: a observação participante (Haguette, 1990; Becker, 1999) e a realização de entrevistas não-diretivas (Chizzotti, 2000), com pessoas que residem, há 50 anos ou mais, no pantanal do Padre Inácio - Jauru, município de Cáceres, sudoeste mato-grossense, Microrregião do Alto Pantanal (IBGE, 2000).

Esse grupo é considerado portador dos saberes aos quais é atribuída a sustentabilidade da área em estudo, pois vivenciam o processo de modernização local. Portanto, para o escopo deste trabalho, serão denominados pantaneiros tradicionais. $\mathrm{O}$ uso desse termo refere-se à tradição, que "enfatiza as noções de continuidade (...) acentua o conjunto de sabedoria coletiva incluído na tradição do grupo" (Silva, 1986).

Na primeira parte do texto, busca-se desenhar um arcabouço teórico sobre o conceito de paisagem, delineando os enfoques associados à cultura e considerando elementos da literatura sobre Desenvolvimento Sustentável. Uma vez estabelecido esse primeiro ponto, descrevem-se os saberes pantaneiros relacionados aos conhecimentos construídos sobre a paisagem natural e, a partir destes, às formas de organização da paisagem cultural que resultaram em aspectos peculiares da cultura material.

Parafraseando Cosgrove (1998) e Sauer (2000), a paisagem cultural é construída a partir de uma paisagem natural pelos grupos sociais. A cultura é a principal protagonista, os elementos naturais constituem o meio, e a paisagem cultural o resultado. Sob a influência 
de uma determinada cultura, mutável através dos tempos, a paisagem apresenta transformações, sendo que uma nova paisagem pode se sobrepor à antiga. A ação que modela a paisagem natural é a própria cultura através da conservação, reprodução e transformação de seus saberes.

\section{Paisagem, cultura e desenvolvimento sustentável}

O termo 'paisagem', segundo o senso comum, se reduz a uma porção do espaço que pode ser observada com um golpe de vista. Essa definição simplista não corresponde às reflexões epistemológicas contemporâneas, que concebem esse conceito de forma multidimensional, apresentando aspectos morfológicos, envolvendo um conjunto de elementos criado pela natureza em conjunto com ação antrópica e suas dimensões funcionais. $\mathrm{O}$ conceito atual de paisagem deve considerar, certamente, diferentes relações entre partes.

As paisagens são históricas, pois sempre resultam das ações das pessoas sobre o ambiente ao longo do tempo e, como ocorrem em determinadas áreas, apresentam uma dimensão espacial. A paisagem é portadora de significados, expressando os valores, as crenças, os mitos e as utopias dos seres que as habitam, tendo portanto uma dimensão cultural (Corrêa \& Rosendahl, 1998).

Berque (1998), considera a paisagem como marca e matriz posto que esta evidencia a relação de determinada sociedade com a área em que habita e revela suas formas de percepção da natureza. A paisagem, como marca, pode ser representada de forma pormenorizada, seus caracteres podem ser descritos, enumerados e analisados.

Esse conceito nos dá a idéia de movimento, transformação e ação das diversas formas de vida sobre o ambiente físico ou natural, os quais vão sendo moldados, resultando na paisagem cultural. Sob esse aspecto é evidente a idéia de mutabilidade, de mudanças que ocorrem de acordo com o momento histórico e os valores políticos, culturais, econômicos que prevalecem em cada sociedade.

A noção de transformações contínuas que podem alterar a paisagem natural e a paisagem cultural está intrínseca também nas 
discussões sobre o Desenvolvimento Sustentável, em particular no arcabouço que trata da cultura como um aspecto importante para a busca da sustentabilidade. Sachs (2000) propõe que a dimensão cultural da sustentabilidade é entendida como um sistema aberto e passível de transformações. Essa característica é uma propriedade compartilhada por diversos autores (e.g. Viertler,1988; Claval,1999) ao referirem-se aos aspectos conceituais da cultura. Considera-se aqui, seguindo esta linha de pensamento, que "sustentabilidade cultural" não significa a manutenção de aspectos inalterados, postura típica dos primórdios do pensamento ambiental, como por exemplo em relação à preservação da natureza. A contextualização atual de sustentabilidade deve considerar componentes que admitem a emergência de novos aspectos culturais que se apropriam e/ou transformam os conhecimentos e valores construídos através dos tempos. Trata-se de uma teia complexa caracterizada por inte-relações fortes entre a cultura e o meio natural, que, de maneira dinâmica, estabelecem um processo de adaptação mútua, em uma dada escala de tempo (e.g., Moran, 1982). A dimensão cultural da sustentabilidade, portanto, como em muitas situações e especificamente para o Pantanal brasileiro, apresenta uma forte influência sobre os componentes econômicos e ambientais de uma dada região e, a partir de um processo de retroalimentação, é influenciada por estes mesmos fatores. Isto justifica toda uma abordagem integrada ambiente-cultura que deve ser tomada como ponto de partida para estudos em biomas tais como o Pantanal.

A Comissão Mundial Sobre Meio Ambiente e Desenvolvimento (1991) aborda a cultura sob dois prismas: o primeiro, e mais enfatizado, menciona os aspectos culturais relacionados aos povos tribais e indígenas, considerados tradicionais; o segundo, aborda os estereótipos culturais construídos em relação a determinados grupos, que acabam por influenciar as condições de vida no planeta.

Em relação aos povos tradicionais, é premente a preocupação com as pressões resultantes do desenvolvimento econômico, colocando em risco seus conhecimentos, pois "tais comunidades são consideradas depositárias de um vasto acervo de experiências (...).Seu desaparecimento constitui uma perda para a sociedade, que teria muito a aprender com suas técnicas tradicionais de lidar com sistemas ecológicos..."( Comissão...1991, p. 125 ). 
Apesar de admitir que seja inevitável o processo de integração das comunidades locais em uma estrutura social e econômica mais ampla, recomenda que sejam asseguradas as necessidades básicas desses povos; entre elas o direito de preservar sua identidade cultural.

É incontestável a importância dessas populações e é consenso que suas elaborações são extremamente interessantes. Porém, ao mencionar determinados grupos, como se só estes fossem portadores de sistemas culturais, transmite-se a idéia de que a cultura só existe em sociedades fechadas e isoladas, excluindo os aspectos da pluralidade da diversidade cultural.

A cultura, entendida como "... a soma dos comportamentos, dos saberes, das técnicas, dos conhecimentos e dos valores acumulados pelos indivíduos durante suas vidas e, (...) pelo conjunto dos grupos de que fazem parte..." (Claval, 1999, p. 63), é um aspecto inerente às sociedades humanas, está presente em todos os grupos sociais, conseqüentemente, deveria ser tratada como um indicador importante para a sustentabilidade das diferentes tipologias de sociedade.

No entanto, grande parte da bibliografia sobre sustentabilidade ambiental menciona a cultura, com raras exceções, sempre ligada ao conhecimento desses povos considerados tradicionais, excluindo outros grupos sociais.

Roué (1997, p. 199), chama a atenção para o que denomina de 'etnocentrismo às avessas' que conduz à idealização dos saberes exóticos, deles tentando extrair, princípios filosóficos para aplicar no contexto social do pesquisador, porque "o estudo dos saberes do Outro sobre a natureza é um exercício difícil, que explicita melhor a transformação das relações com a natureza na sociedade do observador, do que na sociedade observada."

Os modelos de colonização e imposição do desenvolvimento econômico e tecnológico têm provocado processos de degradação ambiental que apresentam uma série de consequiências econômicas, sociais e culturais. Usualmente esses processos afetam as minorias, através do desenraizamento das comunidades de seus espaços étnicos, provocando a destruição das identidades culturais e o esquecimento das práticas tradicionais de uso dos recursos. 
Neste contexto, a cultura é vista sob a égide da ética ambiental fundamentada em dois termos chaves: a conservação da diversidade biológica do planeta e o respeito à heterogeneidade étnica e cultural da espécie humana (Leff, 1998). A construção da paisagem cultural está intimamente relacionada aos sistemas de valores e ao respeito à autonomia das populações para definir seus projetos, mesmo que estes não aceitem mais as antigas formas de uso dos recursos naturais. Nessa constatação reside o verdadeiro desafio do desenvolvimento sustentável.

Embora tenham sido praticados por várias sociedades, desde tempos remotos, os preceitos do desenvolvimento sustentável estão em processo de construção. A idéia de vantagens econômicas tem superado as antigas práticas, e a tarefa que se impõem é justamente escolher as melhores alternativas, dentro dos princípios da sustentabilidade, para atender aos anseios econômicos e de melhoria da qualidade de vida das pessoas ou grupos, amenizando os impactos na paisagem natural.

As paisagens pantaneiras são construídas por atores sociais, entre eles, os que habitam nas áreas rurais, nas fazendas e que representam parcela dos agentes responsáveis pela sustentabilidade deste significativo ecossistema. Este grupo não constitui uma população tradicional nos moldes colocados pela bibliografia sobre desenvolvimento sustentável, porém, algumas famílias que ali residem, por sucessivas gerações, desenvolveram práticas de manejo da pecuária que se repetiram através dos séculos e, a partir do ritmo imposto pelas condições naturais, construíram saberes que resultaram em formas peculiares de organização da paisagem cultural.

\section{Saberes pantaneiros}

\section{Conhecimento e organização da paisagem natural}

Existem várias hipóteses sobre as causas da convivência harmônica dos habitantes das fazendas pantaneiras com a paisagem natural. Entre elas, a vertente que atribui esta situação às condições impostas pela sazonalidade climática, pela altimetria do relevo e pela cobertura vegetal específica. 
O regime tropical de precipitações caracteriza-se por dois períodos distintos: um chuvoso, que vai de outubro a março, e outro seco, no período de abril a setembro. O pantanal da área em estudo passa por um período de inundações moderadas, durante aproximadamente três a cinco meses ao ano (PCBAP, 1997).

Este elemento, associado à baixa altimetria do relevo, constituído por terrenos planos que variam entre 80 e 150 metros, e a presença do Rio Paraguai e seus afluentes, apresenta uma paisagem denominada por Rondon (1972) de "grande teatro inundável" devido à mutabilidade dos cenários naturais nas diferentes épocas do ano.

Durante as cheias, as águas dos rios da Bacia do Paraguai transbordam e estendem-se preguiçosamente sobre a planície, cobrindo a vegetação e acumulando-se nos lugares mais baixos, originando lagoas permanentes ou temporárias denominadas localmente de baías. Algumas delas extravasam durante as enchentes, ligando-se a outras através de cursos d'água chamados de "corixos", quando são permanentes e "vazantes" quando temporários.

Nesta época, só se avistam as "cordilheiras", lugares com cerca de três metros de altura acima do nível da planície (Innocencio, 1988), que representam barreiras ao escoamento das águas superficiais. $\mathrm{Na}$ vazante, as águas começam a baixar, é comum ouvir entre os pantaneiros a expressão "no pantano [pronuncia-se pantâno] já tá secando". As lagoas temporárias transformam-se paulatinamente em barreiros e uma nova estação se anuncia, a seca, que transforma a paisagem natural de forma admirável. Para o transeunte é difícil crer que, até bem pouco tempo, a vegetação estava encoberta e os animais ilhados nas cordilheiras.

O ritmo imposto pela sazonalidade climática e pelas condições geomorfológicas e hidrográficas, influencia as formas de vida e também de certa forma, as atividades cotidianas dos seres humanos.

O sucessivo ritmo das águas nos pantanais possibilita a idéia de ciclos demarcados pelas épocas de cheia-vazante-seca e o surgimento de saberes específicos que permitiram, por mais de três séculos, a prática da pecuária extensiva como principal atividade econômica, sem alterar as condições ecológicas locais. 
A pecuária tradicional desenvolvida nos pantanais caracterizase pela criação de gado de forma extensiva. Os rebanhos são soltos nos pastos nativos, exigindo poucos cuidados por parte do fazendeiro. Neste contexto, a natureza é percebida como a grande responsável pela manutenção da atividade produtiva.

A vegetação original, utilizada durante séculos na alimentação bovina, exige tratos culturais considerados pelas fontes orais como de "limpeza"; ação realizada pela própria natureza, através das águas que se espalham na planície durante as cheias e representam um acontecimento cíclico que renova a pastagem nativa. Esse elemento dispensa o uso de insumos químicos e mão-de-obra humana, efetuandose um controle natural.

Durante a seca, proliferam as 'macegas', vegetação nativa endurecida e fechada que dificulta a pastagem. Para os pantaneiros tradicionais, é tempo da queimada. $\mathrm{O}$ fogo, proposital ou não, limpa o campo exterminando ervas daninhas e animais peçonhentos, como cobras e morcegos que atacam e prejudicam o gado.

O manejo tradicional das pastagens nativas baseia-se no entendimento formulado pela experiência das sucessivas gerações. A utilização do fogo, durante séculos, possui uma conotação cultural, e seu controle pelos órgãos ambientais possibilitou transformações na cultura material, expressas através de mudanças nas técnicas de produção, estimulando o plantio de forrageiras exóticas.

Este fato toma relevância quando a proibição da queimada é um argumento utilizado pelos pantaneiros tradicionais para justificar o desmatamento e a formação de pastagens cultivadas, alegando que sem o fogo para efetuar a limpeza, o gado não têm condições de sobreviver.

As referidas técnicas de manejo são elementos integrantes da cultura material e foram exercidas por aproximadamente trezentos anos, permanecendo em algumas fazendas pantaneiras até o momento histórico atual.

Os espaços construídos, integrantes da paisagem pantaneira, são determinados pela cultura, pela maneira específica de organizálos e dividi-los de forma concreta ou simbólica. Parafraseando Villa 
(2000), o mundo humano é um mundo social, simbólico, histórico e cultural, portanto, produto das sociedades humanas e que pode ser entendido e avaliado dentro dos marcos da cultura que o gera.

As fazendas pantaneiras diferem das outras unidades produtivas do restante do país, apresentando uma organização espacial própria, que usualmente exige um amplo conhecimento da topografia do relevo. Estes saberes foram obtidos pela constante observação do caminho das águas na época das enchentes, dos lugares que secam primeiro na época das vazantes e, também, daqueles que propiciam água para o gado por mais tempo durante o período de estiagem.

Essa lógica é a responsável pela organização e divisão da paisagem natural das tradicionais fazendas pantaneiras, caracterizadas, de forma geral, pelas grandes extensões, resultado das condições naturais e históricas de acesso e posse da terra (Rossetto \& Brasil Jr. 2002a).

As fazendas são, de maneira geral, divididas em regiões com denominações locais: Lagoa Comprida, Catolino, Aguaçú, Couro Especado, Aguapé etc. Estes locais não têm cercas para delimitá-los geograficamente, porém, segundo as fontes orais entrevistadas, o gado de uma região, não se mistura com a outra, fato que ninguém consegue explicar.

A observação do comportamento dos elementos naturais, em cada estação, produz conhecimentos que resultam do senso comum, nas palavras de Geertz (1999), "teríamos, assim, algo como. naturalidade, praticabilidade, leveza. Naturalidade é a mais essencial O bom senso apresenta temas - isto é, alguns temas e não outros como sendo o que são, porque essa é a natureza das coisas. Dá a todos os temas um ar de que isto é óbvio, um jeito de 'isto faz sentido'.'

As porções divididas com cercas são denominadas invernadas, campos de grandes extensões que impossibilitam delimitar seu tamanho. Essas atualmente podem ter pasto nativo ou exótico e são utilizadas para manter o gado que necessita de cuidados especiais. A escolha do local da invernada, leva sempre em conta a presença de mananciais aquíferos: baías, corixos etc. e de capões ou cordilheiras para o gado se proteger na época de frio ou enchentes. É necessário 
que o gado tenha liberdade de andar pelo campo em busca de água e boas manchas de pasto nativo.

O trabalho com o gado no campo exige que os vaqueiros se desloquem em grandes extensões. Na época das águas, as estradas de acesso são encobertas e tornam-se invisíveis na paisagem, entretanto, o pantaneiro possui uma noção de espaço admirável. Apesar da semelhança entre os locais, orienta-se no campo percebendo marcas com significados individuais raramente perdendo o rumo, demonstrando estar adaptado à mutabilidade da paisagem.

Devido às pequenas diferenças altimétricas nas feições do relevo, na época da seca, torna-se difícil distinguir lugares mais altos ou mais baixos, suscetíveis ou não às inundações. Os pantaneiros possuem a capacidade de definir esses locais com segurança, delimitando os lugares destinados à infra-estrutura como habitação, conservação dos instrumentos de trabalho e ao manejo do gado.

Conhecedores das fontes de inundação, ou seja, da dinâmica das águas pluviais e mananciais aqüíferos, priorizam a construção da moradia próxima às baías, alegando a impossibilidade das águas atingirem-na, fato comprovado pela convivência com a sazonalidade das estações climáticas através dos tempos.

As casas são organizadas no espaço geográfico de maneira muito próxima. Não existe distância entre a residência dos proprietários e a dos empregados. A simplicidade das moradias e do vestuário dos grupos sociais dificulta a identificação de fazendeiros e peões. Não existem diferenças aparentes em relação ao mobiliário, tipos de alimentos consumidos. Os locais de higiene pessoal e das refeições são partilhados de forma comunitária. Entretanto, o espaço simbólico da relação entre patrões e empregados possui um limite que não é expresso verbalmente. No momento das refeições, os primeiros a servirem-se dos alimentos são os proprietários e suas famílias, seguidos dos empregados e suas famílias. Esta regra é obedecida também pelas crianças, inclusive nos momentos de festa.

A paisagem cultural do Pantanal do Padre Inácio - Jauru revela, a um só tempo, elementos tradicionais e elementos da modernização, indicando um processo onde os saberes tradicionais se confundem 
com os saberes da modernidade. Alguns permanecem e proliferam com o correr dos anos, assumindo novas identidades, outros desaparecem; porém, sobrevivem na memória dos pantaneiros mais antigos.

Os aspectos da cultura material pantaneira desempenham, na paisagem cultural local, o elo entre a tradição e a modernidade, representando um legado para as gerações atuais e futuras. $\mathrm{O}$ resgate dessas características evidencia a multifuncionalidade das áreas alagadiças e as diferentes formas de uso e conservação da biodiversidade do ecossistema através dos tempos.

\section{Cultura material: reflexo das tradições}

As intervenções humanas na natureza envolvem sua transformação em cultura. As mudanças podem não estar visíveis na paisagem, assumindo significados simbólicos, imperceptíveis ao olhar do estranho, porém, a convivência no local conduz ao desvelar das diversas manifestações da cultura, entre estas a expressividade dos objetos que formam a cultura material, entendida como "... aquilo que o homem cria ou concebe e que utiliza na sua vida quotidiana, de modo a extrair do meio envolvente tudo o que necessita" (Nogueira, 2000, p. 192).

A utilização dos elementos da biodiversidade e sua transformação em objetos permitem o entendimento dos valores inerentes à sociedade que os criou, bem como as condições de vida, os hábitos, a história. A cultura material expressa a atividade intelectual dos seres humanos, em qualquer paisagem ou tempo histórico.

Na perspectiva de Nogueira (2000), os objetos criados por determinada cultura caracterizam-se pela permanência através dos tempos, ou seja, pela intemporalidade e, também pela mobilidade, pois estes circulam entre as sociedades humanas adquirindo significados diversos em mais de um contexto ou lugar. A eles é atribuído o status de testemunhos históricos, veículos de transmissão cultural.

As moradias dos pantaneiros tradicionais constituem-se em marcas da cultura na paisagem natural, ou seja, são dotadas de 
significado cultural. Neste contexto, o objeto deixa de ser uma simples construção necessária à subsistência humana e passa a expressar os conhecimentos adquiridos por sucessivas gerações.

No Pantanal do Padre Inácio - Jauru, algumas casas são construídas com barro retirado das lagoas ou áreas encharcadas e madeira extraída da vegetação nativa. Utilizando estes elementos da paisagem-matriz, os pantaneiros repetem as práticas dos grupos indígenas e não dependem de mão-de-obra especializada, adquirindo suas moradias com maior rapidez, além de terem os custos reduzidos.

A estrutura da casa é feita com madeiras roliças como a pindaíva (Xylopia aromatica), fácil de rachar e plana. Primeiramente, são colocados os barrotes na posição vertical e, na base, prega-se uma madeira na horizontal. Segue-se a cada $20 \mathrm{~cm}$ colocando uma ripa de bambu na mesma posição, rachada ao meio.

O material para compor as paredes é retirado das lagoas na época da vazante, o que facilita o trabalho.Sua busca exige sabedoria para classificar "o barro mais argiloso". Para obter maior consistência e durabilidade acrescenta-se o capim carona (Elyonurus muticus), cortado fino, com aproximadamente $5 \mathrm{~cm}$ de diâmetro e estrume de boi, formando assim uma liga.

Essa mistura é amassada com os pés e jogada na parede com as mãos, ação conhecida no local, como "sopapo". As paredes são alisadas com as próprias mãos e demoram aproximadamente uma semana para secar. Sua estrutura necessita de reparos constantes, sendo sempre recuperadas, pois sofrem rachaduras e a ação de insetos que provocam furos, principalmente em agosto, na época seca.

O teto é feito de uma palmeira denominada acuri (Scheelea phalerata), normalmente são feitas quatro camadas para não entrar água na época das chuvas. O piso é feito com casas-de-cupim que, depois de trituradas e molhadas, apresentam-se lisas e firmes.

Atualmente observa-se a predominância das casas de madeira. Este material é comprado nas serrarias dos municípios vizinhos. Para cobertura, usa-se a telha de barro ou amianto. Usualmente pertencem 
a pessoas de maiores posses e caracterizam-se pela predominância das varandas ao redor de todo seu perímetro e das várias portas que ligam os aposentos à varanda ou um cômodo a outro.

A sazonalidade climática, caracterizada por períodos de alagações anuais, proporcionou o uso de meios de transportes específicos como as diferentes canoas, atualmente raras nos pantanais, confeccionadas com técnicas aprendidas dos indígenas que habitaram a região.

As canoas pantaneiras, que passaram a ser confeccionadas pelos habitantes não-índios, são feitas de um único tronco cavado com machado. As espécies mais utilizadas são: o mogno, conhecido como araputanga (Swietnia macrophylla); o cambará (Vochysia divergens); o guanandi (Calophyllum brasiliense); a chimbuva (Enterolobium contortisiliquum); e o ipê (Iabebuia heptaphylla), denominado localmente de peúva.

Além deste tipo de transporte, utilizava-se também o batelão, espécie de canoa grande com capacidade de até dois mil quilos de carga para carregar mercadorias de maior peso, e a montária, canoa pequena, usada de forma análoga ao cavalo, apropriada para deslizar nos campos alagados e trabalhar o gado durante as cheias e vazantes.

Devido à profundidade das lagoas, estes meios de transporte são movidos por remos compridos nos lugares mais fundos e, nos lugares mais rasos, através da zinga, vara fina e também de larga extensão, que se apoia na calha dos rios e lagoas, direcionando e movendo a embarcação.

Os currais tradicionais são construídos com espécies vegetais nativas, como a carijó (Calycophyllum multiflorum); denominada "madeira branca", por ser bem regular apresentando uma mesma bitola, comprida e resistente. Este tipo de madeira dura aproximadamente três a quatro anos.

Além destes conhecimentos, algumas ferramentas de trabalho foram, por muito tempo, confeccionadas no próprio local e ainda são produzidas em algumas fazendas, a exemplo das cordas e laços, feitos com os couros bovinos e utilizados para amarrar porteiras e no manejo do gado; da buzina, objeto bastante semelhante ao berrante, feita 
com um chifre só, inteiro, onde, na ponta é perfurado um buraco de $20 \mathrm{~mm}$ para sair o som deste instrumento utilizado para chamar o gado.

Os potes de barro utilizados para conservar a água fresca e também como local para armazenar arroz, feijão, farinha de mandioca integram os utensílios de todas as moradias visitadas. Segundo pesquisas arqueológicas, representam vestígios do legado cultural de habitantes pré-históricos.

No Pantanal da área em estudo, existem sítios arqueológicos que evidenciam sua ocupação por grupos ceramistas datados do ano 800 da era cristã. Os resquícios desses povos são compostos também por fragmentos e utensílios cerâmicos de variadas dimensões. Segundo Migliacio (2000), a indústria de cerâmica era bastante desenvolvida nesta região. Os habitantes das aldeias maiores, denominados na literatura arqueológica brasileira como 'tradição Descalvado', produziam grandes vasilhas, conhecidas no pantanal como 'potes' com capacidade para armazenar até 200 litros. Tais potes eram utilizados como urnas funerárias, para armazenagem de produtos agrícolas e para fabricação de uma bebida composta por mandioca e milho fermentado, chamada 'chicha'.

A confecção dos objetos que constituem a cultura material pantaneira expressa os conhecimentos produzidos pelas gerações que habitaram esta paisagem através dos tempos, congregam saberes resultantes das condições impostas pela sazonalidade climática e pela miscigenação da cultura indígena, africana e branca, originando formas peculiares de uso da biodiversidade. Este legado cultural está impresso na paisagem natural, através dos objetos e saberes que constituem a paisagem cultural.

\section{Ruptura entre tradições e modernidade}

Como visto anteriormente, a paisagem pantaneira é moldada pela uma harmonia entre grupos sociais locais e o meio natural, compondo portanto o substrato da paisagem cultural deste bioma. As atividades econômicas tradicionais, baseadas na pecuária extensiva 
e na pesca artesanal, estabeleceram uma dinâmica de uso dos recursos naturais, que moldaram a paisagem e mantiveram um equilíbrio sustentável para a região. O Pantanal brasileiro pode ser considerado um bioma que até a última década apresentava indicadores de qualidade ambiental bastante satisfatórios. Isto se deve principalmente ao fato de as características do manejo da pecuária extensiva pantaneira terem sido adequadas ao equilíbrio estabelecido pelos saberes locais. Na última década o Pantanal brasileiro sofre importantes transformações quanto às suas práticas centenárias de utilização dos recursos naturais, em particular em relação ao manejo do pasto. Trata-se de uma ruptura caracterizada pela indução de necessidades de aumento de produtividade, e, conseqüentemente, pela utilização de tecnologias para pecuária utilizando espécies exóticas de forrageiras com intensificação de rebanhos. A nova geração de fazendeiros e peões pantaneiros que, com concepções diferentes de uso da terra, compartilham o pantanal atual, estabelecem um período de ruptura de tradições. Trata-se de uma ruptura bastante particular, pois ela tem base em uma mudança familiar: os agentes da transformação são em grande parte filhos de pantaneiros tradicionais, que assumem uma nova postura para a condução de seus "negócios rurais".

Nas propriedades pantaneiras, a idéia que se tem é de um momento de transição, onde as características da tradição e da modernidade convivem compondo a transformação da paisagem cultural. Este convívio, porém, não ocorre de forma pacífica. A modernização não só altera as técnicas de trabalho, como também produz novas necessidades, principalmente de produtos industrializados, influencia as relações no interior das famílias e dos grupos e ameaça a paisagem natural, interferindo no ritmo estabelecido durante gerações.

Paradoxalmente, isto também coincide com toda a atual onda conservacionista para o Pantanal, que induz também condições de rupturas culturais através da indução de práticas como o ecoturismo e a pesca desportiva. Parte do Pantanal transforma-se de um lócus de sobrevivência a partir de uma produção local (pecuária e pesca) para um fornecedor de serviços de apoio ao turismo contemplativo a este grande santuário. A visão da paisagem cultural destes dois Pantanais certamente é diferente e a sustentabilidade do processo de 
transformação apresenta uma forte necessidade de regulação do Estado, a partir de políticas públicas sustentáveis.

Em seus diferentes níveis, os programas governamentais para o Pantanal contemplam projetos e programas que visam apoiar tanto atividades produtivas sustentáveis (em particular para a pecuária) como também ações conservacionistas para a manutenção da qualidade ambiental do bioma. Nota-se, porém, que pouco tem sido feito para dar suporte à sustentabilidade cultural da região, que como colocado nos argumentos acima, tem sustentado em parte a paisagem pantaneira na essência que muitos ainda almejam. A ruptura entre o tradicional e o novo estabelece, portanto, pressões sobre o meio ambiente local (natureza e sociedade) que poderiam ser mitigadas por um suporte de políticas públicas integradas, envolvendo atores locais.

\section{Considerações finais}

Não é possível, numa sociedade de mercado, globalizada e competitiva, alguns setores continuarem com práticas que tenham pouco retorno econômico. É necessário admitir que algumas características locais venham a desaparecer e outras possam ressurgir com novas roupagens, com efeitos negativos ou positivos na paisagem natural.

Essa autonomia passa necessariamente pela instrumentalização das pessoas em relação aos cuidados com os elementos naturais sob pena de imprimirem-se marcas negativas na paisagem cultural, independentemente da sua condição étnica, da sua identidade, ou posição na estrutura socioeconômica do grupo.

O pantanal da área em estudo apresenta um índice de desmatamento crescente (Rossetto \& Brasil Jr. 2002-b), embora os órgãos ambientais pertencentes à esfera do poder público estadual justifiquem essa ação como "manejo de pasto", previsto nas leis ambientais. No entanto, o pasto é a própria vegetação nativa que vem sendo retirada sem escrúpulos, resultando em alterações nos ciclos de cheia-vazante-seca, antes previsíveis, e no desaparecimento de algumas espécies de animais. 
A paisagem natural e a paisagem cultural sofreram transformações substanciais nos últimos cinco anos e os pantaneiros tradicionais, antes adeptos das antigas técnicas de convívio com as condições do ecossistema, que resistiam à modernidade, inclusive confrontando seus saberes com as idéias e propostas dos filhos e das gerações subseqüentes, estão sucumbindo às técnicas intensivas, justificadas pela maior rentabilidade econômica.

Neste contexto, a questão que ora se impõe, é como proteger os conhecimentos tradicionais que influenciaram na manutenção do equilíbrio ecológico do pantanal quando os próprios atores mostramse contrários a eles e exigem mudanças? Quais são as alternativas para gerir as transformações na cultura material buscando, de forma coletiva com os habitantes locais, o desenvolvimento sustentável do pantanal?

\begin{abstract}
Despite of being occupied by different social groups since hundreds of years, some parts of rural areas of Mato-Grosso wetlands still preserve a part of their natural characteristics. Cattle raising, the main economic activity, was developed without really changing the basic (pattern) landscapes, and related to it the image of their inhabitants is mentioned as an example of sustainable use of natural elements. Despite this positive stereotype, little is still known concerning such knowledge which often get lost or take other forms due to modernity. The present text is inserted in such perspective, its main objective is to research on Pantanal knowing, which resulted in peculiar forms of mark-landscapes organization and in specific aspects of material culture. The conclusion is that with modernization and transformations on material culture, particularly the substitution of native grass by exotic ones, the balance of pattern landscapes is under threat. The cultural sustainability, understood as an open system, subject to transformations, is an indicator of great relevance to the searching of sustainable development.
\end{abstract}

Key-words: Pantanal, cultural landscape, sustainable development.

Résumé: Malgré l'occupation centenaire du Pantanal Brésilien par des diferents groupes sociaux la plupart de son territoire conserve les characteristiques naturelles. L'elevage, principale activité economique de la region, a pu mantenir la dynamique originale de la paysage, et 
l'image de la population pantaneira est toujours consideré comme un example de utilization durable des resources naturels. C'est une vision positive qui n'est pas tenue en compte pendant le processus de transformation economique de la région, qui privilegie un approche de modernité de la production. Cet article s'insere dans cette perspective, et son objective pricipal c'est de proposer une discussion sur la organization de la paysage et quelques aspects especifiques sur la culture materielle au Pantanal brésilien. On propose une reflexion sur la modernisation de la production, qu'utilise des especes exotiques pour l'élevage et représente une ménace sur la paysage naturelle. Le composant culturel du dévelopment durable, au niveau local, est consideré un des aspectes le plus important pour garder la qualité de l'enviroment et la qualité de vie locales.

Mots-clés: Pantanal, paysage cuturelle, dévelopment durable.

\section{Referências bibliográficas}

BECKER, Howard S. Métodos de pesquisa em ciências sociais. 4.ed. São Paulo: Hucitec, 1999.

BERQUE, Augustin. Paisagem-marca, paisagem-matriz: elementos da problemática para uma geografia cultural. In: CORREAA, Lobato Roberto; ROSENDAHL, Zeny (Org.). Paisagem, tempo e cultura. Rio de Janeiro: EdUERJ, 1998. p.84-91

BORGES, Fernando Tadeu de Miranda. Do extrativismo à pecuária: algumas observações sobre a história econômica de Mato Grosso (1870-1930). Cuiabá: Gráfica Genus, 1991

CABRAL, Octaviano. Histórias de uma região (Mato Grosso, Fronteira Brasil-Bolívia e Rondônia). Rio de Janeiro: Himalaya., 1963.

CÂNDIDO, Antonio. Os parceiros do Rio Bonito: estudo sobre o caipira paulista e a transformação do seu meio de vida. Rio de Janeiro: José Olympio,1964. (Coleção Documentos Brasileiros).

CHIZZOTTI, Antonio. Pesquisa em ciências humanas e sociais. 4.ed. São Paulo: Cortez, 2000.

CLAVAL, Paul. A geografia cultural. Florianópolis: Ed. da UFSC, 1999.

COMISSÃO MUNDIAL SOBRE MEIO AMBIENTE E DESENVOLVIMENTO. Nosso futuro comum. 2. ed. Rio de janeiro: Editora da Fundação Getúlio Vargas, 1991. 
CORRÊA FILHO, Virgílio. Pantanais matogrossenses (devassamento e ocupação). Rio de Janeiro: Instituto Brasileiro de Geografia e Estatística, Conselho Nacional de Geografia,1946.

CORREAA, Roberto Lobato Corrêa; ROSENDAHL, Zeny. Apresentando leituras sobre paisagem, tempo e cultura. In: CORRÊA, Roberto Lobato Corrêa; ROSENDAHL, Zeny (Orgs.). Paisagem, tempo $e$ cultura. Rio de Janeiro: EdUERJ, 1998. p. 7-11

COSGROVE, Denis. A geografia está em toda parte: cultura e simbolismo nas paisagens humanas. In: CORRÊA, Roberto Lobato; ROSENDAHL, Zeny (Orgs.). Paisagem, tempo e cultura. Rio de Janeiro: EdUERJ, 1998. p. 92-103.

COSTA, Maria de Fátima. História de um país inexistente: o pantanal entre os séculos XVI e XVII. São Paulo: Estação Liberdade, Kosmos, 1999.

GEERTZ, Clifford. O saber local: novos ensaios em Antropologia Interpretativa. Petrópolis, RJ: Vozes, 1999.

HAGUETTE, Teresa Maria Frota. Metodologias qalitativas na Sociologia. 2. ed. Petrópolis: Vozes, 1990.

INNOCENCIO, Ney Rodrigues. Hidrografia. In: INSTITUTO BRASILEIRO DE GEOGRAFIA E ESTATÍSTICA. Geografia do Brasil: Região Centro-Oeste. Rio de Janeiro: IBGE, 1988. p.73-90.

INSTITUTO BRASILEIRO DE GEOGRAFIA E ESTATÍSTICA (IBGE). Disponível em: 〈http:wwwibge.gov.br/cidadesat/defauult.php〉

LEFF, Enrique. Saber ambiental: sustentabilidad, racionalidad, complejidad, poder. México: Siglo Ventiuno, 1998.

MIGLIACIO, Maria Clara. A ocupação pré-colonial do Pantanal de Cáceres. 2000. Dissertação (Mestrado) - FFLCH/USP.

MORAN, Emilio. Human adaptability: an introduction to ecological Anthropology. Boulder, CO: Westview Press, 1982.

NOGUEIRA, Flávia. Cultura material: a emoção e o prazer de criar, sentir e entender objectos. Disponível em: <http.geocities.com/sandrix65/ oficiosemocao2.htm> Acessado em: 27 ago. 2002.

PLANO DE CONSERVAÇÃO DABACIADO ALTO PARAGUAI(PCBAP). Diagnósticos do meio físico e biótico: Projeto Pantanal, Programa Nacional do Meio Ambiente. Brasília: PNMA, 1997.

RONDON, Lucídio N. J. Tipos e aspectos do Pantanal - Mato Grosso. São Paulo: Livraria Nobel, 1972. 
ROSSETTO, Onélia Carmem; BRASIL JR., Antonio C. P. Entre cheias e vazantes: características históricas da ocupação e sustentabilidade do Pantanal Mato-grossense. Revista do Instituto Histórico e Geográfico de Mato Grosso (RIGMT), Cuiabá, p. 91-112, 2002a.

ROSSETTO, Onélia Carmem; BRASIL JR., Antonio C.P. Cultura material e modernização econômica: elementos para discussão da sustentabilidade ambiental dos pantanais mato-grossenses. In: ROSSETTO, Onélia Carmem; BRASIL JR., Antonio C. P (Orgs.). Paisagens pantaneiras \& sustentabilidade ambiental. Brasília: Ministério da Integração Nacional, Universidade de Brasília, 2002 b. p. 15-36.

ROUÉ, Marie. Novas perspectivas em etnoecologia: "saberes tradicionais" e gestão dos recursos naturais. In: CASTRO, Edna; PINTON, Florence (Orgs.). Faces do trópico úmido: conceitos e novas questões sobre desenvolvimento e meio ambiente. Belém: Cejup, UFPA-NAEA, 1997.

SACHS, Ignacy. Caminhos para o desenvolvimento sustentável. Rio de Janeiro: Garamond, 2000.

SILVA, Benedicto (Coord.). Dicionário de Ciências Sociais. Rio de Janeiro: Editora da Fundação Getúlio Vargas, 1996.

SAUER, Carl O. A morfologia da paisagem. In: CORRÊA, Roberto Lobato Corrêa; ROSENDAHL, Zeny (Orgs.). Paisagem, tempo e cultura. Rio de Janeiro: EdUERJ, 1998. p. 12-74.

VIERTLER, Renate Brigitte. Ecologia cultural: uma Antropologia da mudança. São Paulo: Ática, 1988.

VILLA, Mariano Moreno. Dicionário de pensamento contemporâneo. São Paulo: Paulus, 2000. 
